\title{
Coherence Design of CNC Technology Professional Curriculum
}

\author{
Cheng Xianmin ${ }^{\text {a }}$, Zhu Yu \\ Dalian vocational \& technical college, Liaoning Dalian \\ acxmtc1@163.com, ${ }^{\mathrm{a}} \mathrm{zy}-\mathrm{dlvtc} @ 163 . c o m$
}

Keywords: coherence design, professional curriculum, CNC machining, cultivate

\begin{abstract}
Different from traditional teaching, coherence design of CNC technology professional curriculum is to integrate the fragments of the courses. Choosing appropriate workpiece as carrier, train students to plan machining process, program, machine and inspection. It stimulates students' learning enthusiasm, so their comprehensive vocational ability can be improved greatly.
\end{abstract}

\section{Introduction}

The specialty construction will finally reflect in curriculum system, course content and teaching mode ${ }^{[1]}$. For Numerical Control Technology specialty, by research study on talent demand, the occupation post for graduate are determined, deduce vocational ability acquired by the post, convert to professional ability, and at last construct the curriculum system and course content.

Designing Numerical Control Technology curriculum, linked projections are adopted. In the professional curriculum system, construct a complete process and manufacturing of one or more parts, which helps to form the teaching system really based on the whole process of part design and manufacturing. For the students guided learning the smooth transition of curriculum is realized effectively. Each new stage of learning can quickly get started. Students may gradually learn and master new knowledge and skills. These form ultimately a completely system of knowledge and ability. In college-enterprise cooperation mode, enterprise can provide their own representative products as teaching carrier. During the design, analysis and manufacturing of the parts, a targeted training can be implemented, and achieve a good connection between enterprise practice and college education.

\section{The defect of the independent design of the professional courses}

For the traditional construction of professional courses, teachers usually design their courses separately, not considering connection between every courses of whole professional curriculum system. This may result in unnecessary knowledge duplication in some courses and cannot improve student's progressive ability ${ }^{[2]}$.

\subsection{The connection between professional basic courses and professional courses}

The professional basic course content is relatively single. Although it covers all the necessary knowledge of the profession, the students forget the knowledge soon after examination because the lack of practical case. In the subsequent professional courses, when professional basic knowledge is needed, students do not know how to start, and they are all at sea when open the teaching material. 
This is because the following professional courses suddenly raise more high requirements and are not connected effective with professional basic courses, and then there is a gap between ability requirements of courses. These easily make students lost in the beginning of the course study, also may lead students to rejection of the study gradually, and finally give up the course or just pass the examination.

\subsection{The effective connection between professional courses}

In the traditional professional course design, the teaching case of every professional course is not consistent. This result in different parts used to select cutting tool, apply machine, plan machining process, made NC programming and machine. Students have no overall cognition when they learn every subject. This makes a lot of difficulty to enhance the vocational ability.

To keep the coherence and connected between CNC technology professional courses, the problem to solve is how to realize coherence effectively, how to stimulate students' interest in learning and give them confidence in learning. All about these are main task in the construction of specialty, curriculum system and content of teaching.

\section{Construction of CNC Technology professional curriculum system}

\subsection{Professional curriculum system framework}

According to the research result of the relevant industries, enterprises and vocational colleges and the student's own development needs, the educational objective is determined ${ }^{[3,4]}$. The education objective of CNC technology specialty is to train highly skilled personnel with all-round development of moral qualities, intellectual ability, physical fitness and aesthetic appreciation, who master the knowledge of CNC machine, cutting tool, fixtures and others related CNC machining. The students will have the capacity of CNC machining and part measuring. The student can work in process planning, NC programming, NC machine operation, NC machine maintenance and part quality inspection, etc.

According the talent demand research, the professional ability is determined. Construct curriculum system as "learning and training alternately", "ability increased progressive", "course certificate integration" and "college enterprise coeducation". Course content is determined. The NC curriculum system framework constructed is as follow table 1.

\section{2 "1141" talent cullivation mode}

NC technology specialty adopts " 1141 " talent cultivation mode. The first " 1 " is "a guide", that is, "guided by vocational activity", which is to solve the problem of who the specialty is cultivated for. The second " 1 " is "a main clue", that is, "cultivation of professional ability as the main clue", is to solve the problem of what sort of talent cultivated. "4" is "four stages", that is, "cultivation according to four ability progression stages", is to solve the problem of cultivating way. In the first stage (the first and second semester), Common compulsory courses and professional basic courses are completed, and students' basic skills of machining process. In the second stage (the third and forth semester), finish professional compulsory courses and train the professional core competencies. In the third stage (the fifth semester), finish the courses which promote ability and complete comprehensive training of $\mathrm{CNC}$ machining. These cultivate professional development ability. In the fourth stage (the sixth semester), finish the internship in enterprise. These can enhance students' vocational ability in the real production environment of enterprise. The third " 1 "is "a core", that is, "development of professional quality as core", which is to solve how to cultivate the students. 
Table 1 NC technology curriculum system

\begin{tabular}{|c|c|c|c|c|}
\hline category & number & course & class hour & credit \\
\hline \multirow{6}{*}{$\begin{array}{l}\text { professional } \\
\text { basic } \\
\text { course }\end{array}$} & 1 & Mechanical drawing & 96 & 6 \\
\hline & 2 & Tolerance and measurement technology & 32 & 2 \\
\hline & 3 & Metal materials and heat processing & 32 & 2 \\
\hline & 4 & Fundamental of mechanical design & 96 & 6 \\
\hline & 5 & Mechanical CAD technology & 40 & 2.5 \\
\hline & 6 & Hydraulic and pneumatic technology & 48 & 3 \\
\hline \multirow{14}{*}{$\begin{array}{l}\text { professional } \\
\text { course }\end{array}$} & 1 & Metal cutting tool & 32 & 2 \\
\hline & 2 & Metal cutting machine tool & 48 & 3 \\
\hline & 3 & Machining process & 84 & 5.5 \\
\hline & 4 & CNC lathe programming and operation & 48 & 3 \\
\hline & 5 & CNC milling machine programming and operation & 48 & 3 \\
\hline & 6 & CNC machine electrical control & 80 & 5 \\
\hline & 7 & Typical parts CNC machining & 40 & 2.5 \\
\hline & 8 & CAD/CAM (UG) & 84 & 5.5 \\
\hline & 9 & Multi axis NC machining & 40 & 2.5 \\
\hline & 10 & CNC professional English & 28 & 2 \\
\hline & 11 & Maintenance and overhaul of CNC machine & 60 & 4 \\
\hline & 12 & Commissioning and assembly of electromechanical equipment & 60 & 4 \\
\hline & 13 & Precision detection technology & 24 & 1.5 \\
\hline & 14 & Advanced manufacturing technology & 24 & 1.5 \\
\hline \multirow{10}{*}{$\begin{array}{l}\text { Professional } \\
\text { practice } \\
\text { course }\end{array}$} & 1 & Fitter skill practice & 60 & 2 \\
\hline & 2 & Lathe operation practice & 30 & 1 \\
\hline & 3 & Milling machine operation practice & 30 & 1 \\
\hline & 4 & CNC machine operation practice & 30 & 1 \\
\hline & 5 & EDM machine practice & 30 & 1 \\
\hline & 6 & CNC lathe operation practice & 60 & 2 \\
\hline & 7 & CNC milling machine operation practice & 60 & 2 \\
\hline & 8 & Typical parts CNC machining operation practice & 30 & 1 \\
\hline & 9 & Vocational skill practice & 90 & 3 \\
\hline & 10 & Graduation exercitation practice & 480 & 16 \\
\hline
\end{tabular}

\section{Coherence design of the professional curriculum}

Effective transition of teaching content between the professional courses can be combined with the project teaching method. Choosing the appropriate project, Set up a good bridge between the professional basic courses, the professional courses and professional practice courses of professional curriculum system. Focus on these projects, guide students to establish their confidence and interest gradually, and to study autonomously by instance to draw inferences.

The project must meet the teaching requirements of the professional basic courses, professional courses and practice courses. As the carrier, the teaching case should have authenticity, integrity, typicality and inspiring characteristics. It should meet the following criteria:

\subsection{Select teaching cases according to the practicalities of enterprise}

Screen some typical parts fitted to teaching as production cases, so that can close to the actual 
production, get students closer to work post, stimulate students to complete the task. These make students use what they learn to their practice work. The professional ability, team work and communication are trained, thus improve the vocational comprehensive ability. The students can enter the job as soon as possible after they graduate.

\subsection{The knowledge involving in professional courses should be typical}

Task completed in cases should reflect the professional ability and vocational ability necessary to the graduate's first work post. The student can be NC process designer, NC programmer, operator, maintenance workers and part inspector. Given the part machining, they can analyze the part drawing, prepare the NC process, write NC program, operate NC machine to accomplish part and quality inspection. Selecting the appropriate teaching cases many courses can share these cases to complete the work task. These can achieve the teaching content coherence of professional curriculum.

\subsection{Moderate complexity}

If the case selected is too simple, the goal of improving students' comprehensive ability can not be achieved. On the contrary, if the case is too complex, it will make students flinch, thus, losing interest in work can not be better to complete the task. We can choose the cases according to the requirements of secondary and senior NC professional qualification, which is convenient for students to accept.

\subsection{Generate work results easily}

When students learn the professional course they finish part of the task applying the knowledge and skills which they obtained. When the task of the case is completed, students can complete the workpiece machining, and qualified parts are available. These enable the students to experience the pleasure of success, and can stimulate students' learning enthusiasm.

\section{Coherence design of the professional courses content}

We must obtain overall training objectives of NC technology specialty, avoid invalid repetition of professional knowledge between every course, and especially avoid missing of important knowledge. When determine the course content, teacher of every course should discuss together, communicate and coordinate with each other. Thus design the coherent curriculum content, which commitment to cultivate students' comprehensive professional ability together.

We choose the work task which is not only from practice, but also suitable for teaching. OBP course can prepare for following courses; meanwhile the following courses can strengthen and consolidate OBP courses. These can make a multi effect on promotion of students' ability.

\section{Conclusions}

Exploration the coherence of different stages of curriculum, not only to meet the professional knowledge teaching and professional skills training, but also to stimulate students' interest in learning, and enable students to establish confidence in learning gradually.

Practice has proved that good coherence between the professional basic courses and professional courses or between professional courses not only improves the students' interest in learning, but also cultivates students' ability to analyze and solve problems. It also pulls theory and practice closer, so every student can obtain knowledge easily. 


\section{References}

[1] Tingliao Li and Jincheng Zhang: The Curriculum System Construction of Management Information System in Chinease Finance and Economics. Proceedings of 2015 International Conference on Education and Educational Research(EER2015 V 8):102-106.

[2] HeRongyu, ShanWuxiong and BaiChangcheng: Research on the Linkage of Curriculum System of Secondary and Higher Vocational Education Based on Post Abilities. VOCATIONAL AND TECHNICAL EDUCATION, 2014,2:32-35.

[3] Zhou Xiaoqing: Analysis on Vocational Machinery Manufacturing. SCI-TECH INNOVATION \& PRODUCTIVITY, 2014,10:30-31.

[4] Quan Junzheng: Curriculum System Research on Talent Training Mode of "School-enterprise integration" in Hotel Management Major. Proceedings of 2011 3rd IEEE International Conference on Information Management and Engineering, 2011:98-103. 